\title{
Industry Collaboration
}

National Cancer Institute

\section{Source}

National Cancer Institute. Industry Collaboration. NCI Thesaurus. Code C19468.

Collaboration by $\mathrm{NCl}$ with industry (usually pharmaceutical) for cancer research 